\title{
Sociodemographic Correlates of Four Indices of Blood Pressure and Hypertension among Older Persons in Japan
}

\author{
Shieva Davarian $^{a} \quad$ Eileen Crimmins $^{a} \quad$ Atsuhiko Takahashi $^{b}$ Yasuhiko Saito $^{\mathrm{b}, \mathrm{c}}$ \\ ${ }^{a}$ Davis School of Gerontology, University of Southern California, Los Angeles, Calif., USA; b School of Medicine, and \\ 'Advanced Research Institute for the Sciences and Humanities, Nihon University, Tokyo, Japan
}

\section{Key Words}

Blood pressure · Elderly · Hypertension · Japan

\begin{abstract}
Background: High blood pressure is a significant risk factor for cardiovascular disease and mortality. Japan has traditionally had higher levels of measured blood pressure than many Western countries, and reducing levels of hypertension has been a major focus of Japanese health policy over recent decades. In the West, hypertension is strongly associated with sociodemographic and behavioral (smoking and body mass index, BMI) factors; studies of the association between sociodemographic factors and biological indicators have not been fully explored in the elderly population of Japan using nationally representative survey data. Objective: To describe hypertension prevalence rates with increasing age and to examine the link between sociodemographic and behavioral factors (including age, gender, education, residence, smoking, and BMI) and measures of blood pressure and overall hypertension in the Japanese population aged $\geq 68$ years. Methods: Data were collected in 2006 during the fourth wave of the Nihon University Japanese Longitudinal Study of Aging, a nationally representative sample of those $\geq 68$. The analytic sample includes 2,634 participants. Pulse pressure, systolic, diastolic, and mean blood pressure, as well as hypertension, were regressed on sociodemographic and behavioral factors. Results: There is
\end{abstract}

no significant difference in the prevalence of overall hypertension by age for men and women from ages 68-69 to $90+$. Higher BMI and older age were linked to higher blood pressure and higher chance of having hypertension. More years of education and being female were associated with a lower likelihood of measured hypertension. Smoking, rural residence, and living alone were not significantly associated with the outcome measures. Conclusion: The increase in hypertension with higher BMI raises concerns about future health in Japan as BMI increases. The lack of a relationship between smoking and any measure of blood pressure or hypertension is an indicator that smoking may have different effects in Japan than in other countries. Because there is no effect of living alone on blood pressure, compliance with drug regimes may not be enhanced by living with others in Japan.

Copyright $\odot 2013$ S. Karger AG, Basel

\section{Introduction}

High blood pressure is a significant risk factor for cardiovascular disease and mortality [1]. Japan has traditionally had higher levels of measured blood pressure than many Western countries. As a result, decreasing levels of hypertension have been a major focus of Japanese health policy over recent decades $[2,3]$; a combination of an increase in antihypertensive medication usage $[3,4]$

\section{KARGER}

E-Mail karger@karger.com

www.karger.com/ger
(C) 2013 S. Karger AG, Basel

0304-324X/13/0595-0392\$38.00/0
Shieva Davarian

USC Davis School of Gerontology

3715 McClintock Ave.

Los Angeles, CA 90089-0191 (USA)

E-Mail davarian@usc.edu 
and population-based interventions to reduce salt intake has contributed to declining levels of hypertension in recent years [5]. Despite these gains, hypertension prevalence rates still remain relatively high in Japan [6]. In the West, hypertension is strongly associated with sociodemographic factors $[7,8]$; studies of the association between sociodemographic factors and biological indicators have not been fully explored in the elderly population of Japan using nationally representative survey data. Better understanding of these associations will allow us to develop more effective policies and interventions to improve health outcomes and reduce health inequalities. We hypothesize that sociodemographic factors will be associated with blood pressure levels and hypertension in Japanese elderly.

In this paper, we examine four indices of blood pressure, systolic blood pressure (SBP), diastolic blood pressure (DBP), pulse pressure (PP), and mean blood pressure (MBP) as well as overall hypertension. SBP tends to increase with age, although the relationship is not as clear among older age groups in Japan $[9,10]$, and most researchers and clinicians agree that it is important in predicting risk in older populations [11]. On the other hand, DBP decreases in the elderly populations [11]. As a result of changes in SBP and DBP, PP, which is the difference between the two, has been suggested as a better predictor of risk for cardiovascular disease and mortality in the elderly $[12,13]$. Studies have suggested that both PP and $\mathrm{MBP}$, which is based on DBP and $\mathrm{PP}$, are better indicators of cardiovascular risk in Asian populations, so we include them in our analyses [13-15].

In general, studies conducted in Western countries have shown that higher blood pressure (SBP, DBP and $\mathrm{PP}$ ) is associated with lower socioeconomic status (SES), of which education is an indicator $[7,16,17]$. One mechanism that has been proposed for the role of SES is through the associated educational advantage, particularly the health-specific knowledge and better ability to follow medical advice that comes with more education [18]. On the other hand, the literature on links between SES and health in Japan is mixed; some studies have shown that, as in other industrialized countries, people with higher SES tend to have better health outcomes $[19,20]$, whereas others have shown the association does not exist among the elderly and may differ by gender in Japan [21].

Urban/rural residence $[22,23]$ and living arrangement (i.e. living alone or with others) [24] are two other sociodemographic characteristics that have been associated with differential health outcomes in Japan, with rural residence and living alone associated with worse health outcomes. One study found that stroke mortality tended to be higher in rural areas of Japan [22], whereas the association between living alone and health outcomes is less consistent; some researchers report lower mortality [24] and others report worse self-rated health [25].

Interestingly, gender is a mediating factor in the relationship between living alone and worsened health in Japan, with elderly men who live alone having worse outcomes than women [26]. In general, gender is linked to increased levels of blood pressure and hypertension in some countries, with men having an earlier onset but women having higher prevalence at older ages [27, 28]. However, gender differences in hypertension in the elderly population of Japan are small compared to those in the West; on the other hand, gender differences in specific aspects of hypertension, such as high DBP, are larger in Japan [29]. Studies on the association of gender on blood pressure levels in Japan have focused on younger age groups; therefore, it is still not known how gender influences blood pressure, and subsequently hypertension, in this elderly population.

Behavioral factors also influence blood pressure and hypertension. Higher body mass is thought to be a risk factor for hypertension, particularly when the body mass index (BMI) is in the obese range $(\geq 30)$ [11]. However, research findings are inconsistent on the relationship between obesity and elevated blood pressure levels in Japan, particularly at older ages [30, 31]. Smoking is another well-known risk factor for cardiovascular disease [11]; researchers have shown that smoking increases blood pressure, and even counters the positive effects of some antihypertensive medication [32]. However, acute and longterm effects of smoking on hypertension are still not clear among the Japanese population [33].

In order to gain a better understanding of the association between sociodemographic characteristics, behavioral factors and health outcomes, we examine the association of blood pressure and hypertension, and education, rural/urban residence, living arrangement, gender, age, smoking, BMI, and antihypertensive medication usage among the elderly Japanese population.

\section{Methods}

Data Sources

This study utilizes data collected in 2006 during the fourth wave of the Nihon University Japanese Longitudinal Study of Aging (NUJLSOA). NUJLSOA is a nationally representative sample of the Japanese population aged $\geq 65$ years at baseline collected by the $\mathrm{Ni}$ hon University Tokyo, Japan. The first wave of data was collected 
in 1999, and subsequent waves were conducted in 2001, 2003, and 2006. Younger participants were added at the second and third waves so as to remain nationally representative of the $\geq 65$ years population at each wave. New participants were not added at the fourth wave in 2006, so that the fourth wave contains data from participants aged $\geq 68$ years. The survey has included questions on hypertension and self-reports of antihypertensive medication usage. In addition, at the fourth wave of the survey, blood pressure measurement was added to the survey. Complete information on the design and methods of the study can be found on the website of the Nihon University [34].

The fourth wave of the survey includes 3,403 participants of whom $68 \%$ participated in the collection of blood pressure measurements $(n=2,330)$, and of this sample 2,073 had a measured blood pressure recording and responded to all sociodemographic, health behavior, and medication questions included in the analysis and constitute the total analytic sample.

The sample is weighted to represent a national population, and for this analysis weights were adjusted to account for having missing data on measured blood pressure. The adjustment was created by multiplying the normalized weight of the sample by the inverse of the predicted probability that each participant would have a blood pressure measurement. The predicted probability was based on age, sex, and level of education. The adjusted weight was used in all analyses.

\section{Measurements}

Blood Pressure Collection

Blood pressure in NUJLSOA was measured using the digital OMRON HEM-762 (OMRON, Kyoto, Japan); validation information for the device is provided by the manufacturer [35]. For blood pressure measurement, the participant was typically in a seated position, and the recording was performed on the left arm by the interviewer. Blood pressure was measured three times with approximately $1 \mathrm{~min}$ between measurements and the average of the three readings was used for analysis. If fewer than three readings were performed, then the average of those readings was included.

Blood Pressure

The measures of blood pressure included in this study were SBP ( $\mathrm{mm} \mathrm{Hg}$ ), DBP (mm Hg), PP (mm Hg) and MBP (mm Hg). PP was calculated by subtracting DBP from SBP. MBP was computed as $\mathrm{DBP}+(\mathrm{PP} / 3)$.

\section{Hypertension}

Measured hypertension was defined as having SBP $\geq 140 \mathrm{~mm} \mathrm{Hg}$ or a DBP $\geq 90 \mathrm{~mm} \mathrm{Hg}$ [36]. Overall hypertension prevalence was indicated by either having measured hypertension or self-reported antihypertensive medication usage. The question of whether or not participants were using blood pressure medication was asked of those participants who responded affirmatively to ever having experienced hypertension. Table 1 provides descriptive measures on the blood pressure variables.

\section{Sociodemographic Characteristics}

SES, measured by years of education, was divided into three categories, $<8$ years, $9-11$ years, and $>12$ years. For our analyses, we selected the middle education group (9-11 years) as the referent group. Rural residence, living alone, and gender were coded as dichotomous variables. Age was categorized into six groups (68-
Table 1. Descriptive statistics for NUJLSOA sample $(\mathrm{n}=2,073)$

\begin{tabular}{lc}
\hline SBP, mm Hg & $155.2(22.7)$ \\
DBP, mm Hg & $82.1(12.4)$ \\
PP, mm Hg & $73.2(18.2)$ \\
MBP, mm Hg & $106.5(14.2)$ \\
Prevalence of high SBP, \% & 73.41 \\
Prevalence of high DBP, \% & 24.73 \\
Measured hypertension, \% & 74.15 \\
Overall hypertension (measured high or & \\
$\quad$ medication use), \% & 81.87 \\
Education, \% & \\
$\quad \leq 8$ years & 30.07 \\
$\quad$ 9-11 years & 39.28 \\
$\quad \geq 12$ years & 30.65 \\
Rural residence, \% & 28.5 \\
Living alone, \% & 14.46 \\
Female, \% & 53.66 \\
Age, years & $75.8(7.56)$ \\
Use of antihypertensive medication, \% & 35.50 \\
Nonsmoker, \% & 37.72 \\
Former smoker, \% & 50.11 \\
Current smoker, \% & 12.18 \\
BMI & $22.6(4.0)$
\end{tabular}

Values for SBP, DBP, PP, MBP, age and BMI are expressed as mean (SD).

$69,70-74,75-79,80-84,85-89$, and $\geq 90)$. In order to observe agerelated differences in blood pressure and hypertension, we selected the youngest age group as the referent category for all the analyses and examined differences of the other age groups from this group.

Health Behavior and Medication

Smoking status was separated into three categories; never smoked, former smoker, and current smoker because the effect of smoking on blood pressure was not clear from existing literature. Never smokers were used as the referent group. BMI was used as a continuous measure and was calculated by dividing selfreported weight $(\mathrm{kg})$ by the square of self-reported height $\left(\mathrm{m} ; \mathrm{BMI}=\mathrm{kg} / \mathrm{m}^{2}\right)$. Use of antihypertensive medication among those who said they had experienced hypertension was coded as a dichotomous variable, indicating medication usage or not.

\section{Ethical Concerns}

The study procedure was approved by the Ethics Committee of the School of Medicine, Nihon University.

\section{Statistical Methods}

All analyses were conducted on Statistical Analysis System 9.1 (SAS Institute Inc., Cary, N.C., USA). Regression analysis of blood pressure and hypertension measures on sociodemographic indicators was used in order to examine the independent effect of each of the variables while controlling for the others. Analysis of continuous measures of blood pressure was based on ordinary least squares (OLS) regression (table 2). Dichotomous indicators of measured hypertension and overall hypertension were regressed on independent variables using the logistic regression procedure (table 3). 
Table 2. Regression coefficients from OLS regressions of blood pressure regressed on sociodemographic characteristics and health behavior $(n=2,073)$

\begin{tabular}{|c|c|c|c|c|}
\hline & SBP & DBP & PP & MBP \\
\hline$\leq 8$ years of education ${ }^{1}$ & -1.96 & -1.12 & -0.84 & -1.40 \\
\hline$\geq 12$ years of education & -1.51 & -0.19 & -1.32 & -0.63 \\
\hline Rural residence & 0.63 & 0.85 & -0.22 & 0.78 \\
\hline Living alone & -1.74 & 0.25 & -1.99 & -0.42 \\
\hline Female & -0.66 & -0.55 & -0.11 & -0.58 \\
\hline $70-74$ years old ${ }^{2}$ & 0.65 & -1.34 & 1.98 & -0.68 \\
\hline $75-79$ years old & 1.47 & $-3.22^{* *}$ & $4.68^{* *}$ & -1.66 \\
\hline 80-84 years old & $5.17^{*}$ & $-2.71^{*}$ & $7.87^{* * *}$ & -0.08 \\
\hline $85-89$ years old & $5.37^{*}$ & $-4.42^{* *}$ & $9.79^{* * *}$ & -1.16 \\
\hline $90+$ years old & 3.11 & $-4.25^{*}$ & $7.36^{* *}$ & -1.80 \\
\hline \multicolumn{5}{|l|}{ Antihypertensive } \\
\hline medication & $3.17^{* *}$ & 0.14 & $3.03^{* * *}$ & 1.15 \\
\hline Former smoker ${ }^{3}$ & -0.69 & 0.67 & -1.35 & 0.22 \\
\hline Current smoker & 0.83 & 0.62 & 0.21 & 0.69 \\
\hline BMI & $0.74^{* * *}$ & $0.33^{* * *}$ & $0.41^{* *}$ & $0.47^{* * *}$ \\
\hline $\mathrm{R}^{2}$ & 0.02 & 0.03 & 0.05 & 0.02 \\
\hline d.f. & 14 & 14 & 14 & 14 \\
\hline \multicolumn{5}{|c|}{$\begin{array}{l}19-11 \text { years of education was used as the referent category. } \\
268-69 \text { was used as the referent category. } \\
{ }^{3} \text { Nonsmokers was used as the referent category. } \\
{ }^{*} \mathrm{p}<0.05 ;{ }^{* *} \mathrm{p}<0.01 \text {; }^{* *} \mathrm{p}<0.001 .\end{array}$} \\
\hline
\end{tabular}

\section{Results}

\section{Descriptive Statistics}

Table 1 shows the descriptive statistics for the blood pressure, hypertension, sociodemographic, health behavior, and medication measures. Average SBP for the sample (155.5 $\mathrm{mm} \mathrm{Hg}$ ) was much higher than $140 \mathrm{~mm} \mathrm{Hg}$, which is the criterion for systolic hypertension. However, DBP for the sample $(82.2 \mathrm{~mm} \mathrm{Hg})$ was lower than $90 \mathrm{~mm} \mathrm{Hg}$, the cutoff value for hypertension. Measured hypertension was found in about three fourths (74.15\%) of the sample, whereas the prevalence of overall hypertension was $81.87 \%$. Less than half the sample $(35.50 \%)$ reported antihypertensive medication usage. These figures confirm previously reported high levels of hypertension among the older Japanese population.

\section{Blood Pressure by Age and Gender}

Before we examined the associations of blood pressure and hypertension with sociodemographic variables using multivariate analyses, we examined levels of SBP, DBP, PP, and MBP by age and gender (fig. 1). There were no significant differences by gender at any age in these
Table 3. Odds ratios and 95\% CI from logistic regressions of hypertension regressed on sociodemographic characteristics and health behavior $(\mathrm{n}=2,073)$

\begin{tabular}{|c|c|c|c|c|}
\hline & \multicolumn{2}{|c|}{$\begin{array}{l}\text { Measured hypertension } \\
\text { (either high systolic or } \\
\text { diastolic) }\end{array}$} & \multicolumn{2}{|c|}{$\begin{array}{l}\text { Overall hypertension } \\
\text { (measured high or } \\
\text { medication) }\end{array}$} \\
\hline & OR & $95 \% \mathrm{CI}$ & OR & $95 \%$ CI \\
\hline$\leq 8$ years of education ${ }^{1}$ & 0.96 & $0.78-1.19$ & 1.10 & $0.86-1.40$ \\
\hline$\geq 12$ years of education & 0.79 & $0.65-0.95$ & 1.03 & $0.83-1.28$ \\
\hline Rural residence & 1.05 & $0.88-1.26$ & 1.11 & $0.90-1.37$ \\
\hline Living alone & 0.87 & $0.69-1.08$ & 0.85 & $0.66-1.10$ \\
\hline Female & 0.81 & $0.67-0.97$ & 0.95 & $0.77-1.17$ \\
\hline $70-74$ years old ${ }^{2}$ & 1.00 & $0.78-1.29$ & 1.20 & $0.91-1.58$ \\
\hline $75-79$ years old & 1.21 & $0.90-1.64$ & 1.83 & $1.31-2.57$ \\
\hline 80-84 years old & 1.37 & $0.98-1.91$ & 1.76 & $1.21-2.55$ \\
\hline $85-89$ years old & 1.22 & $0.83-1.82$ & 2.05 & $1.30-3.23$ \\
\hline $90+$ years old & 0.97 & $0.57-1.67$ & 2.29 & $1.17-4.46$ \\
\hline \multicolumn{5}{|l|}{ Antihypertensive } \\
\hline medication & 1.35 & $1.13-1.60$ & & \\
\hline Former smoker ${ }^{3}$ & 1.16 & $0.94-1.43$ & 1.05 & $0.82-1.33$ \\
\hline Current smoker & 1.13 & $0.84-1.52$ & 0.96 & $0.69-1.34$ \\
\hline BMI & 1.06 & $1.03-1.09$ & 1.13 & $1.10-1.17$ \\
\hline$\overline{\chi^{2}}$ & 64.59 & & 93.58 & \\
\hline d.f. & 14 & & 13 & \\
\hline $\mathrm{BIC}$ & -113 & & -134 & \\
\hline pseudo-R2 & 0 & & 0 & \\
\hline
\end{tabular}

Values in bold indicate significant findings.

${ }^{1} 9-11$ years of education was used as the referent category.

${ }^{2} 68-69$ was used as the referent category.

${ }^{3}$ Nonsmokers was used as the referent category.

measures. There was little change with age in level of SBP and MBP in either men or women at these older ages. There was some reduction in DBP at older ages $(\geq 75$ years). Among females 68-69 years old, average DBP was $84 \mathrm{~mm} \mathrm{Hg}$ (95\% CI: 82-86 mm Hg) versus $79 \mathrm{~mm} \mathrm{Hg}$ (95\% CI: $77-81 \mathrm{~mm} \mathrm{Hg}$ ) for the $85-89$ age group. The drop in DBP occurred at a slightly younger age among males. As a result of the stability of SBP and this decline in DBP, PP increases slightly with age.

\section{SBP and DBP among Respondents with Overall \\ Hypertension}

Figure 2 presents histograms indicating the distribution of SBP and DBP among all respondents with overall hypertension and among respondents with overall hypertension who were on medication. Slightly more than $20 \%$ of overall hypertensives on medication had an SBP $<140 \mathrm{~mm} \mathrm{Hg}$, compared to only $10 \%$ of all overall hypertensions who had an SBP $<140 \mathrm{~mm} \mathrm{Hg}$. Similarly, 
Fig. 1. Average blood pressure by age and sex.

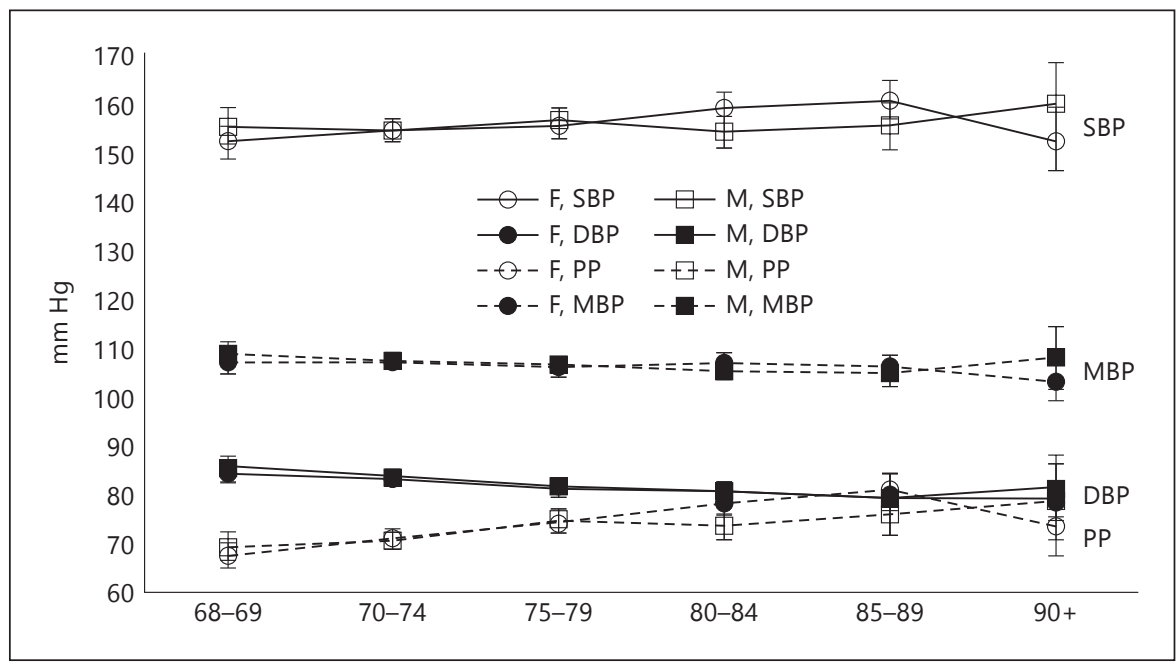

Fig. 2. Distribution of SBP (a) and DBP (b) of respondents with overall hypertension.

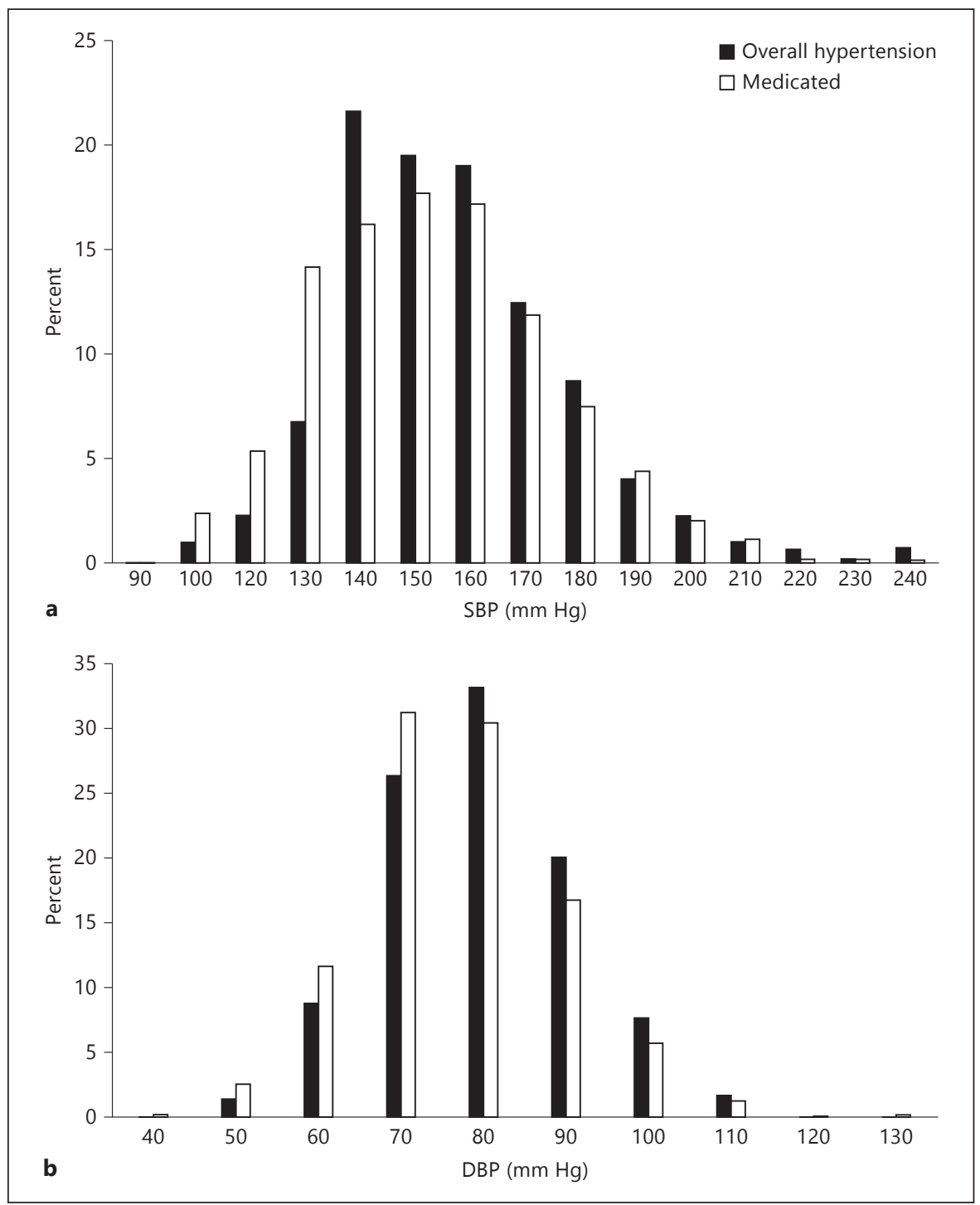


Fig. 3. Prevalence of hypertension and

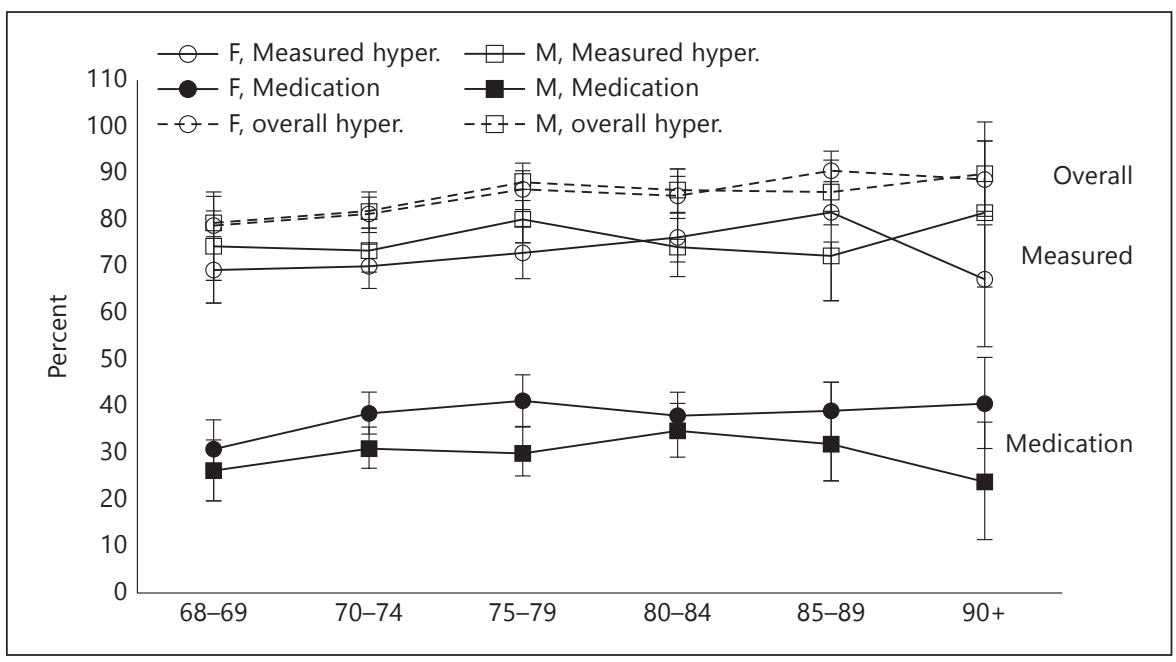
medication usage by age and sex.

around $75 \%$ of medicated overall hypertensives had a DBP $<90 \mathrm{~mm} \mathrm{Hg}$, compared to about $70 \%$ of all overall hypertensives. This suggests that medication interventions may be reducing blood pressure levels to some degree, but seem to work more effectively on DBP.

\section{Prevalence of Hypertension and Antihypertensive Medication Usage}

Figure 3 displays the prevalence of overall hypertension, measured hypertension, and antihypertensive medication usage by age and gender; there was no clear pattern of increase with age in any of these measures when differences by age group were examined. The only significant difference by gender was found in medication usage in the 75-79 age group; women had slightly higher antihypertensive medication usage, 41\% (95\% CI: 35.85$46.89 \%$ ) versus $30 \%$ (95\% CI: $24.97-35.46 \%$ ) in men.

The only significant difference with age was seen in the prevalence of overall hypertension among women, where women under age 75 had a lower prevalence of overall hypertension compared to women aged 85-89 years old, $79 \%$ (95\% CI: $73-85 \%$ ) versus $90 \%$ (95\% CI: 86-95\%), respectively.

\section{OLS Regressions of Blood Pressure on \\ Sociodemographic Characteristics and Health \\ Behavior}

Table 2 contains regression coefficients from OLS regressions of SBP, DBP, PP, and MBP on education, rural residence, living alone, gender, age, antihypertensive medication usage, smoking, and BMI. These equations control for confounding variables so that the effect of each variable is shown with controls for the others. There were no significant associations between years of education, rural residence, living alone, and gender on any of the blood pressure measures; thus, none of these sociodemographic characteristics appears to be a significant predictor of blood pressure among older Japanese persons. With controls, SBP was significantly higher for those in the 80-84 (5.17, p < 0.05) and 85-89 (5.37, p < 0.05 ) age groups than for those aged 68-69 (the reference category). On the other hand, with controls, higher age was associated with lower DBP for all older age groups, except 70- to 74-year-olds. PP was significantly higher for each age group, except 70-74, compared to the 68-69 (referent) age group. Age had no influence on MBP.

Antihypertensive medication usage was significantly associated with higher SBP $(3.17, \mathrm{p}<0.01)$ and, since PP is calculated by subtracting DBP from SBP, PP also increased $(3.03, \mathrm{p}<0.001)$. This positive relationship probably reflects the tendency for the use of drugs among those with the most severe hypertension as well as the inability of drugs to reduce blood pressure to low levels in many patients.

Higher BMI was significantly associated with higher SBP (0.74, p < 0.001), DBP (0.33, p < 0.001), PP (0.41, $\mathrm{p}<0.01)$, and $\mathrm{MBP}(0.47, \mathrm{p}<0.001)$. Smoking was not significantly associated with blood pressure.

Logistic Regressions of Hypertension on

Sociodemographic Characteristics and Health

Behavior

Table 3 contains the odds ratios and 95\% confidence limits from logistic regressions of hypertension on educa- 
tion, urban/rural residence, living alone, gender, age, antihypertensive medication usage, smoking, and BMI. Higher education had a significant effect on measured hypertension; those with 12 years or more of schooling had $21 \%$ less chance of having measured hypertension. There was no association between education and overall hypertension. There was no significant effect of rural residence and living alone on either measured or overall hypertension. Women were $19 \%$ less likely to have measured hypertension (0.81, CI: 0.67-0.97), but there was no significant difference between men and women in overall hypertension. Age was associated with an increase in the relative likelihood of having overall hypertension. For those 90+, the likelihood of having overall hypertension was more than twice that of those 68-69. On the other hand, there was no significant difference with age in measured hypertension.

Those who were on antihypertensive medication had a higher likelihood of having measured hypertension (1.35, CI: 1.13-1.60). BMI was significantly associated with both measured and overall hypertension; one unit of increase in BMI increased the relative likelihood of having measured hypertension by 6\% (CI: 1.03-1.09) and overall hypertension by $13 \%$ (CI: $1.10-1.17)$. Smoking was not significantly associated with hypertension.

\section{Discussion}

The intent of this paper was to provide a more complete analysis of the association between blood pressure and sociodemographic characteristics and health behaviors within the older Japanese population using nationally representative survey data. We found significant links between BMI and each of our measures of blood pressure and hypertension; in each case, higher BMI was linked to higher blood pressure or more hypertension. The only other variable, which was fairly consistently related to differences in blood pressure when other controls were in the equations, was age. Without the controls in the equations, most measures of blood pressure did not change much with age; only DBP was lower at higher ages and PP increased with age. However, when the controls were added, older participants had higher SBP, PP, and overall hypertension, and lower DBP.

The lack of relationship between some of the other variables and well-measured blood pressure is of interest because it again demonstrates how different the process of health determination is in Japan. Rural residence was not significantly associated with any of the outcome measures; and we should note that when we substituted rural residence in childhood into the equation, the relationship was not significant. Thus, we examined the effect of both early and late life environment across Japan and found no differentials in blood pressure. The lack of relationship of hypertensive measures with living arrangements would tend to indicate that compliance with drug regimens is not enhanced by living with others. The lack of a relationship between past or current smoking and any measures is a strong indicator that smoking may have different effects in Japan, a country where heart disease is relatively low when compared to other low-mortality countries [2]. In fact, some researchers have found that SBP and DBP in Japanese men who are current smokers was significantly lower than in non- and ex-smokers [37], whereas others have found that smoking is associated with the onset of systolic hypertension among Japanese men [38].

We should note that higher education was only significantly linked to lower measured hypertension when the use of antihypertensives was included as a control variable; this is also true for gender differences, where the only significant difference by gender was higher measured hypertension among males when antihypertensive use was included in the equation. The fact that the effects of education and being male disappear when antihypertensive medication use is part of the dependent variable means that differences in use of antihypertensives was what caused the significant findings. Additionally, medication seems to be more effective at reducing DBP than at reducing SBP. Reductions in DBP compared to SBP might actually be more beneficial in reducing mortality among the oldest old; some researchers have found lower mortality rates among men 85 years or older with an $\mathrm{SBP} \geq 180 \mathrm{~mm} \mathrm{Hg}$ and higher mortality among both genders with a DBP $\geq 90 \mathrm{~mm} \mathrm{Hg}$ [39].

We can offer some explanations for the lack of significant associations between hypertension in Japan and a number of variables that are linked with hypertension in other countries. Studies examining effects of education on various health outcomes in Asian countries suggest that the effects of education might be more limited in these countries than in Western countries $[17,40]$. This may be related to a lack of differences by education in behaviors, lifestyle, and diet in Asian countries. Further study of the mediating variables might add to our understanding. It is also possible that the provision of universal and comparable health care in Japan might play a role in the lack of social differences in hypertension. More research needs to be conducted to understand the extent to which sociodemographic characteristics are associated, or not, with other biomarkers and health outcomes in Japan. Future studies 
in Japanese cohorts should also compare the association between mortality and blood pressure with that observed in other countries, as well as the longitudinal relationship between blood pressure and other aspects of health.

The strong link between weight and hypertension adds to the concern about future health in Japan as BMI increases. While BMI is low in Japan, relative to most other countries, it has been steadily increasing [23]. If we use our results to calculate the likelihood of having overall hypertension for people of different characteristics, we can see the effect of increasing weight in the population. For instance, a woman 75-79 years of age with a BMI of 22.7 (the average in the sample), high education, who did not smoke and lived with someone in an urban area, would be predicted to have a $65 \%$ probability of having overall hypertension. With higher BMI at the level of overweight $(\mathrm{BMI}=25)$, the probability would increase to $68 \%$, and with the onset of obesity (BMI +30$)$, it would rise to $74 \%$. Given that BMI is increasing in the population, these findings indicate a force toward increasing blood pressure in Japan. Similarly, the aging of the aged in Japan is another force toward increasing blood pressure, and improvements need to be made in monitoring that population. As an example of the effect of age, when age is increased from 68-69 years to 90 years or older, the risk of overall hypertension for a woman with the same characteristics as above and average BMI $\left(22.7 \mathrm{~kg} / \mathrm{m}^{2}\right)$ increases from 55 to $70 \%$.
We used multiple measures of blood pressure and hypertension in our analyses. The results indicate that MBP does not differ with age, while SBP, DBP, and PP vary with age when examined in multivariate analyses including sociodemographic and behavioral variables. Defining hypertension by measured blood pressure or including the use of medications in the definition of hypertension produces different links to sociodemographic measures. The different links between different measures and outcomes may partly explain the sometimes conflicting results in the literature.

Finally, we should note that our results are limited to people over 68 years of age, and they would probably differ if younger people were included in the analysis. Our results indicate only limited differences by age in the measures of blood pressure without controls for other variables. This may be partly explained by mortality among those with higher more adverse blood pressure and by the fact that much of what we think of age-related physiological change occurs before old age.

\section{Acknowledgements}

This study was partially supported by the 'Academic Frontier' Project for Private Universities: matching fund subsidy from MEXT (Ministry of Education, Culture, Sports, Science and Technology), 2006-2010 and the National Institute on Aging of the United States (P30AG017265).

\section{References}

1 Okayama A, Kadowaki T, Okamura T, Hayakawa T, Ueshima H, The NIPPON DATA80 Research Group: Age-specific effects of systolic and diastolic blood pressures on mortality due to cardiovascular diseases among Japanese men (NIPPON DATA80*). J Hypertens 2006;24:459-462.

2 Glei DA, Meslé F, Vallin J: Diverging trends in life expectancy at age 50: a look at causes of death; in Crimmins EM, Preston SH, Cohen B (eds): International Difference in Mortality at Older Ages: Dimensions and Sources. Washington, The National Academies Press, 2010, pp 64-104.

3 Ikeda N, Gakidou E, Hasegawa T, Murray CJL: Understanding the decline of mean systolic blood pressure in Japan: an analysis of pooled data from the national nutrition survey, 1986-2002. Bull World Health Organ 2008;86:978-988.

4 Mori H, Ukai H, Yamamoto H, Saitou S, Hirao K, Yamauchi M, Umemura S: Current status of antihypertensive prescription and associated blood pressure control in Japan. Hypertens Res 2006;29:143-151.
5 Ikeda N, Saito E, Kondo N, Inoue M, Ikeda S, Satoh T, Wada K, Stickley A, Katanoda K, Mizoue T, Noda M, Iso H, Fujino Y, Sobue T, Tsugane S, Naghavi M, Ezzati M, Shibuya K: Japan: universal health care at 50 years 1 : what has made the population of Japan healthy? Lancet 2011;378:1094-1105.

-6 Hozawa A, Ohkubo T, Kikuya M, Yamaguchi J, Ohmori K, Fujiwara T, Hashimoto J, Matsubar M, Kitaoka H, Nagai K, Tsuji I, Satoh H, Hisamichi S, Imai Y: Blood pressure control assessed by home, ambulatory and conventional blood pressure measurements in the Japanese general population: the Ohasama study. Hypertens Res 2002;25: 57-63.

7 Gliksman MD, Lazarus R, Wilson A, Leeder SR: Social support, marital status and living arrangement correlates of cardiovascular disease risk factors in the elderly. Soc Sci Med 1995;40:811-814.

8 van Rossum CTM, van de Mheen H, Witteman JCM, Hofman A, Mackenbach JP, Grobbee DE: Prevalence, treatment, and control of hypertension by sociodemographic factors among the Dutch elderly. Hypertension 2000; $35: 814-821$.

-9 Kagiyama S, Fukuhara M, Ansai T, Matsumura K, Soh I, Takata Y, Sonoki K, Awano S, Takehara T, Iida M: Association between blood pressure and mortality in 80 -year-old subjects from a population-based prospective study in Japan. Hypertens Res 2008;31: 265-270.

$\rightarrow 10$ Kagiyama S, Takata Y, Ansai T, Matsumura K, Soh I, Awano A, Sonoki K, Yoshida A, Torisu T, Hamasaki T, Nakamichi I, Takehara T, Iida M: Does decreased diastolic blood pressure associate with increased mortality in 80-year-old Japanese? Clin Exp Hypertens 2009;31:639-647.

11 DiGiovanna AG: Circulatory system; in DiGiovanna AG (ed): Human Aging: Biological Perspectives, ed 2. San Francisco, McGrawHill, 1999, pp 68-92.

$\checkmark 12$ Benetos A, Safar M, Rudnichi A, Smulyan H, Richard JL, Ducimetière P, Guize L: Pulse pressure: a predictor of long-term cardiovascular mortality in a French male population. Hypertension 1997;30:1410-1415. 
13 Okada K, Iso H, Cui R, Inoue M, Tsugane S: Pulse pressure is an independent risk factor for stroke among middle-aged Japanese with normal systolic blood pressure: the JPHC study. J Hypertens 2011;29:319-324.

14 Asia Pacific Cohort Studies Collaboration: Blood Pressure Indices and Cardiovascular Disease in the Asia Pacific Region: A Pooled Analysis. Hypertension 2003;42:69-75.

15 Miura K, Soyama Y, Morikawa Y, Nishijo M, Nakanishi Y, Naruse Y, Yoshita K, Kagamimori S, Nakagawa H: Comparison of four blood pressure indexes for the prediction of 10 -year stroke risk in middle-aged and older Asians. Hypertension 2004;44:715-720.

16 Kiely DK, Gross AL, Kim DH, Lipsitz LA: The association of educational attainment and SBP among older community-living adults: the Maintenance of Balance, Independent Living, Intellect and Zest in the Elderly (MOBILIZE) Boston Study. J Hypertens 2012;30 1518-1525.

17 Colhoun HM, Hemingway H, Poulter NR: Socio-economic status and blood pressure: an overview analysis. J Hum Hypertens 1998;12: 91-110.

18 Yong V, Saito Y: Are there education differentials in disability and mortality transitions and active life expectancy among Japanese older adults? Findings from a 10-year prospective cohort study. J Gerontol B Psycho Sci Soc Sci 2012;67:343-353.

$\checkmark 19$ Fujino Y, Tamakoshi A, Iso H, Inaba Y, Kubo T, Ide R, Ikeda A, Yoshimura T, JACC study group: A nationwide cohort study of educational background and major causes of death among the elderly population in Japan. Prev Med 2005;40:444-451.

$>20$ Fukuda Y, Nakamura K, Takano T: Wide range of socioeconomic factors associated with mortality among cities in Japan. Health Promot Int 2004;19:177-187.
21 Honjo K, Hiroyasu Iso H, Manami Inoue M, Shoichiro Tsugane S, the JPHC Study Group: Education, social roles, and the risk of cardiovascular disease among middle-aged Japanese women: the JPHC study cohort. Stroke 2008 39:2886-2890.

22 Nishi N: Baseline cardiovascular risk factors and stroke mortality by municipality popula tion size in a 19-year follow-up study-NIP PON DATA80. J Epidemiol 2008;4:135-143.

23 Yoshiike N, Kaneda F, Takimoto H: Epidemiology of obesity and public health strategies for its control in Japan. Asia Pac J Clin Nutr 2002;11:S727-S731.

24 Saito E, Sagawa Y, Kanagawa K: Social support as a predictor of health status among older adults living alone in Japan. Nurs Health Sci 2005;7:29-36.

25 Murata C, Takaaki K, Hori Y, Miyao D, Tamakoshi K, Yatsuya H, Sakakibara H, Toyoshima $\mathrm{H}$ : Effects of social relationships on mortality among the elderly in a Japanese rural area: an 88-months follow-up study. J Epidemiol 2005;15:78-84.

26 Fujino Y, Matsuda S: Prospective study of living arrangement by the ability to receive informal care and survival among Japanese elderly. Prev Med 2009;48:79-85.

27 Crimmins EM, Hayward MD, Ueda H, Saito Y, Kim J: Life with and without heart disease among women and men over 50. J Women Aging 2008;20:5-19.

28 Kim JK, Alley D, Seeman T, Karlamangla A, Crimmins E: Recent changes in cardiovascular risk factors among women and men. J Womens Health 2006;15:734-746.

29 Crimmins EM, Vasunilashorn S, Kim JK, Hagedorn A, Saito Y: A comparison of biological risk factors in two populations: the United States and Japan. Popul Dev Rev 2008;34:47-482.

30 Matsumura K, Ansai T, Awano S, Hamasaki T, Akifusa S, Takehara T, Abe I, Takata Y: Association of body mass index with blood pressure in 80-year-old subject. J Hypertens 2001; 19:2165-2169.
31 Wakabayashi I: Relationships of body mass index with blood pressure and serum cholesterol concentrations at different ages. Aging Clin Exp Res 2006;16:461-466.

32 Omvik P: How smoking affects blood pressure. Blood Press 1996;5:71-77.

33 Narkiewicz K, Kjeldsen SE, Hedner T: Is smoking a causative factor of hypertension? Blood Press 2005;14:69-71.

34 Nihon University Japanese Longitudinal Study of Aging 2004. http://gero.usc.edu/CBPH/ nujlsoa/ (English), http://www.nihon-u.ac.jp/ affiliate_institute/information_networking/ services/nujlsoa// (Japanese); retrieved December 4, 2012.

35 Shirasaki O, Asou Y, Takahashi Y: New clinical validation method or automated sphygmomanometer: a proposal by Japan ISOWG for sphygmomanometer standard. Blood Press Monit 2007;12:381-383.

36 World Health Organization: Global health observatory data repository: Blood pressure. 2012.http://apps.who.int/gho/data/?vid=2464; retrieved January 28, 2013.

37 Ohkubo YT, Miyamoto Y, Suwazono E, Kobayashi E, Nogawa K: An association between smoking habits and blood pressure in normotensive Japanese men. J Hum Hypertens 2002; 16:91-96.

38 Dochi M, Sakata K, Oishi M, Tanaka K, Kobayashi E, Suwazono Y: Smoking as an independent risk factor for hypertension: a 14year longitudinal study in male Japanese workers. Tohoku J Exp Med 2009;217:37-43.

39 Satish S, Freeman DH, Ray L, Goodwin JS: The relationship between blood pressure and mortality in the oldest old. JAGS 2001;49: 367-374.

40 Kaneda T, Zimmer Z: Education, gender, and functional transitions among Indonesian elderly. JAMA 2007;22:303-322. 